\title{
La gestión estratégica de las ciudades. El caso de una ciudad media de Sudamérica: Mar del Plata (Argentina)
}

\section{Ignasi Brunet Icart}

Universitat Rovira i Virgili

ignasi.brunet@urv.cat

\section{Rafael Böcker Zavaro}

Universitat Rovira i Virgili

rafael.zavaro@urv.cat

\section{Resumen}

Desde la década de 1990, en Argentina se vive bajo una "plaga» de planes estratégicos, a consecuencia de la municipalización de la crisis del Estado y de los procesos de ajuste macroeconómico. Los planes estratégicos presentan la ventaja de permitirnos identificar, para cada caso concreto de planificación, los grupos de interés que pretenden, mediante la instrumentalización de una política pública específica, aumentar su peso dentro y fuera del municipio. Por otra parte, y éste es el objetivo del presente artículo, los planes estratégicos son el reflejo del crecimiento y de la consolidación del corporativismo en el ámbito local y, concretamente, de la gestión privada de intereses públicos.

Palabra clave: planes estratégicos, corporativismo, ámbito local.

Abstract. The strategic management of the cities. The case of an average city of South America: Mar del Plata (Argentina)

Since the 1990s, Argentina lives under a strategic planning "plague» consequence of the transference of the state crisis to the district level and of the macroeconomic policies. Strategic plans have the advantage of allowing us to identify, for each particular case of planning, the interest groups which pretend, through the instrumentation of a specific public policy, to gain weight inside and outside the district. On the other side, and this being the purpose of the present article, strategic plans are a reflection of the growth and consolidation of corporatism at the local level and, specifically, of the private management of public interest.

Key words: strategic planning, corporatism, local level.

\section{Sumario}

Introducción Síntesis de resultados

Contextualización Conclusión

Marco teórico y metodología Bibliografía

de la investigación 


\section{Introducción}

En Argentina, la crisis del Estado se resolvió mediante su municipalización, lo que explica que un importante número de gobiernos municipales comenzasen a buscar y a ensayar caminos alternativos a los modelos tradicionales de gestión pública del desarrollo. Dentro del nuevo estilo de gestión del desarrollo que implementaron las administraciones locales de la década de los noventa, reapareció la planificación con la pretensión de orientar sobre las posibilidades y los hándicaps de los municipios o las regiones. En un contexto de generalización del riesgo en las vidas individuales de los argentinos debido al nuevo modelo de acumulación — de valorización financiera-, proliferaron los planes estratégicos, como reflejo del nuevo sistema de gestión privada del interés público. Bajo este nuevo modelo de gestión, las autoridades y las instituciones locales comenzaron a tomar conciencia de que con un estado «en retirada», tanto de las políticas de fomento de las economías regionales, como de las políticas de compensación social, el papel que deberían asumir los gobiernos locales debía romper con los esquemas tradicionales de gestión de las burocracias públicas, lo que explica la urgencia con la que algunas ciudades argentinas han puesto en marcha proyectos de desarrollo local enmarcados en planes estratégicos de actuación. Planes que, bajo el control de grupos para la defensa de intereses particulares, no garantizan un modelo integral de desarrollo local, una visión de bienestar común donde entren una máxima variedad de intereses no estrictamente económicos o políticos. De ahí que el objetivo de este trabajo es mostrar cómo un específico plan estratégico constituye una concreción de corporativismo local, que, como estrategia y realidad política, arranca de la convicción de que con la introducción de criterios privados y de mercado pueden resolverse los problemas que aquejan a la acción de las burocracias públicas.

\section{Contextualización}

Con la desaceleración económica de la década de 1970, se iniciaron dinámicas de recomposición de la política y de los territorios, lo cual provocó cambios en la política fiscal y de redistribución de la renta. El cambio esencial en la fiscalidad fue la tendencia a dar mayor peso a la eficiencia frente a la equidad. Esto se tradujo en reformas fiscales basadas en tres principios: (1) reducir los incentivos perversos de la imposición directa anterior; (2) potenciar el principio de equidad horizontal - tratar igual a los iguales - en detrimento de la vertical - tratar de forma diferente a los distintos-, y (3) simplificar administrativamente el impuesto. Cambios que eran el reflejo de las nuevas políticas estructurales de oferta orientadas a reducir la excesiva intervención y regulación estatal, lo que se plasmó en la aceptación generalizada del principio de subsidiariedad.

Bajo este principio quedó establecido que el sector público sólo debía hacer aquello que demostrara hacer mejor que la iniciativa privada, lo que determi- 
nó los siguientes efectos (Segura, 2005): 1) el primero fue el proceso de liberalización de mercados, que, en muchos casos, pasaron a ser de ámbito mundial. La reducción de barreras arancelarias y otros obstáculos al comercio mundial, los avances en la construcción de áreas supranacionales como la Unión Europea (UE), las reformas de los mercados de trabajo, la liberalización de los mercados de capitales y de divisas son ejemplos significativos de este proceso; 2) el segundo fue el cambio en las políticas regulatorias. Frente a la regulación y la proliferación de toscos instrumentos de intervención cuantitativa que interferían en el funcionamiento de los mercados, las nuevas prácticas regulatorias se fueron haciendo más sensibles a generar incentivos compatibles con un comportamiento eficiente de los mercados, y 3) el tercero fue el intenso proceso de privatización de empresas públicas y de externalización de diversos servicios públicos.

Detrás del principio de subsidiariedad, estaba la creencia de que ya no se daban las condiciones para una expansión rentable utilizando métodos keynesianos, lo que llevó a economistas y gobiernos al convencimiento de que, puesto que las políticas de demanda — monetaria y fiscal — tenían, a largo plazo, efectos inapreciables y difíciles de predecir, el objetivo de la política económica debería concentrarse en favorecer el funcionamiento eficiente de los mercados y crear las condiciones de estabilidad que favorecieran el crecimiento sostenido de la economía (Lal, 1983). Esto trajo consigo que, frente a la política económica keynesiana, las políticas de oferta se apoyaran en los siguientes dos pilares: 1) las políticas económicas debían perseguir como objetivo fundamental la estabilidad, ser neutrales y sustituir la discrecionalidad por reglas de comportamiento estrictas y conocida por los agentes económicos que, de esta forma, verían reducida su incertidumbre y podrían incorporarlas en sus decisiones económicas, y 2) la influencia del sector público en los procesos de asignación de recursos debía instrumentarse mediante un adecuado sistema de incentivos y no por medio de la intervención directa en los procesos productivos, dando mayor protagonismo a los mercados y eliminando en lo posible los obstáculos para su funcionamiento flexible.

En el caso argentino, no sólo estos dos pilares marcaron la política económica iniciada a mediados de los años setenta, sino que, a partir de la instauración de la dictadura militar, se modificaron los elementos centrales de la doctrina vigente, al abandonar la concepción de que el crecimiento económico y la inclusión social constituían pilares básicos para superar los conflictos sociales, reemplazándola por otra encaminada a disciplinar y controlar a los sectores populares mediante la desindustrialización, la concentración del ingreso y la represión. Interrumpido de este modo el proceso anterior de industrialización por sustitución de importaciones, el nuevo modelo de acumulación basado en la valorización financiera se afianzó en las siguientes décadas con los sucesivos gobiernos democráticos hasta desembocar en la crisis de 2001. Concretamente, la valorización financiera se refiere a la importancia que gana el sector financiero en la asignación del excedente, pero, también, da cuenta de un proceso más general que estriba en la colocación de excedente, por parte 
de empresas no financieras, en una amplia gama de activos financieros, tanto en el mercado interno como en el internacional (Basualdo, 2001). Modelo de acumulación inexplicable, por otra parte, sin el apoyo del enfoque neoclásico del desarrollo. Enfoque que cuestionó el papel activo del Estado tachándolo de intervencionismo excesivo. Intervencionismo que traía aparejada una inmensa ineficiencia en el funcionamiento de la economía, por lo que se aplicaron una serie de políticas encaminadas al ajuste fiscal, la privatización de empresas estatales y a la desregulación de la economía, dentro de la cual la desestructuración del mercado de trabajo va a tener un papel central. Hay que ajustar primero, se dijo, para poder «desarrollar» después; una forma reveladora de definir las prioridades, y que refleja el posicionamiento hegemónico del enfoque neoliberal que asimila el desarrollo al crecimiento.

La hegemonía del enfoque neoliberal obedeció en gran medida al descrédito del análisis keynesiano, a la crisis del estructuralismo latinoamericano y a la decadencia de las perspectivas críticas - neomarxistas - del desarrollo, en las que el subdesarrollo era una consecuencia del proceso continuo de extracción por los monopolios industriales del centro del excedente generado en la periferia (Amin, 1974, 1985). Descrédito que explica la influencia del pensamiento neoclásico en las ideas y los programas de los principales organismos internacionales cuyas críticas al intervencionismo gubernamental y el culto a las virtudes del libre mercado procuraron una redefinición del Estado en todos sus frentes, tal y como quedó reflejado en la década de los ochenta con las denominadas "políticas de estabilización» seguidas de una política de ajuste estructural, y en la década de los noventa en el llamado "Consenso de Washington". Consenso que pretendía dar respuesta a la crisis de la deuda externa que afloró a partir del 15 de agosto de 1982, cuando México anunció la imposibilidad de cumplir con los pagos de su primer paquete de medidas de ajuste estructural para salir de la crisis. Crisis provocada, según esta perspectiva, por el excesivo crecimiento del Estado, por la ineficiencia de las empresas públicas, por la excesiva regulación, proteccionismo y populismo económico que imposibilitaban el control del déficit público. Este conjunto de medidas - consistentes en una primera etapa de estabilización de la economía eliminando la inflación y el déficit exterior como principales desequilibrios macroeconómicos, y en una segunda etapa de ajuste estructural, encaminada a generar un modelo de desarrollo orientado al mercado- se convertiría en el modelo prototipo del Consenso de Washington, y que ensalzaba el desarrollo gradual, continuo, armónico, y el libre juego de las fuerzas de oferta y demanda (la lógica perfecta del mercado) (Williamson, 1990).

Estos aspectos van a configurar el proceso denominado por Beck (1998a) como "globalismo», y que califica una integración económica mundial bajo el dominio de una práctica y de una ideología económica, social y política neoliberal o neoclásica. Práctica e ideología que incorpora lo que el Grupo de Lisboa (1995) llamó «evangelio de la competencia». Un evangelio para el que la competencia es la respuesta a casi todos los problemas económicos. Si empeora el problema del desempleo, entonces es necesario aumentar la compe- 
titividad. Si existe un problema creciente de pobreza en algunos países, entonces hay que ser más competitivo. Asimismo, la educación y la capacitación deben orientarse más a la panacea de la competencia. Como resultado: la crisis del 2001. Crisis producto del retroceso de la estructura productiva, de la contracción del sistema productivo, de la dislocación de la estructura productiva nacional, y ello a consecuencia de que el capital extranjero adquirió industrias, o fragmentos de industrias, que supeditó a sus propias estrategias e intereses, y, cómo no, a la apertura irrestricta al exterior. Apertura que tuvo como consecuencia que las bases de la existencia material de Argentina pasase a depender de agentes extranjeros, que no dudaban en abandonarlas, transformarlas o destruirlas cuando no servían a los intereses de un elevado beneficio económico.

\section{Marco teórico y metodología de la investigación}

En la década de los noventa, el temor de perder terreno en la competencia internacional se apoderó de los gobiernos en el norte y en el sur, en el este y en el oeste. No perder terreno en el área económica se convirtió en una obsesión que dominaría las políticas de desarrollo industrial, y que se planteaban bajo la consideración de que las fuentes de crecimiento endógeno están llamadas a desempeñar un papel más importante que las exógenas. En este sentido, se pondrá el énfasis en el potencial de las pequeñas empresas y en la capacidad empresarial local para revitalizar las economías regionales y locales (Becattini, 1992, 2002; Bellandi, 2004, 2006). Y ello a consecuencia de la confluencia de: 1) una línea de investigación empírica que surge de la interpretación de los procesos de desarrollo industrial en localidades y regiones del sur de Europa, en donde se observó el éxito de la organización de la producción en distritos industriales, y 2) una línea de investigación teórica que emergió del intento de encontrar una noción de desarrollo que permitiera la acción pública para el desarrollo de localidades y regiones atrasadas (Vázquez, 1999).

De esta confluencia, emergió un concepto de desarrollo basado en actores, recursos y capacidades locales, y mediante el cual se establecieron políticas de naturaleza regional y local que se sustentaban en la creencia de que los territorios han de tratar de obtener ventajas competitivas mediante la valorización de sus recursos y la diferenciación de sus actividades productivas (Storper, 1990; Vázquez, 2005). Territorios abocados a emprender sendas de desarrollo endógeno que les permitiera mejorar su posición competitiva y, al mismo tiempo, lanzar estrategias que incentivaran la creación de empresas innovadoras. Se recupera y se confirma, así, la idea de Pollard (1987) de que la industrialización fue un proceso fundamentalmente regional, en el sentido de que no se industrializan los países sino determinadas regiones de estos países. Perspectiva que, por otro lado, confirmaba la tesis de un gran número de trabajos sobre el postfordismo, y para la que la evolución del capitalismo conducía al resurgimiento de espacios locales de transferencia progresiva de competencias de coordinación (Jessop, 1994; Lash y Urry, 1987; Harvey, 1989a, 1989b). Se trata, para Sassen (1996), de una transformación en la articulación de la sobe- 
ranía y del territorio; transformación en la que el Estado se vacía de su sustancia en beneficio de instituciones supranacionales y de construcciones sociopolíticas como las ciudades (Bagnasco y Gales, 1997).

En este marco, la idea de desarrollo ha resurgido fortalecida, lo cual ha generado un importante cambio en su conceptualización. Así, frente a la visión del desarrollo exógeno, de carácter redistributivo, que incentivaba la atracción de capitales y empresas externas para impulsar el crecimiento económico de las regiones periféricas, se abre camino la aproximación del desarrollo endógeno que considera que las economías de las regiones y localidades pueden crecer utilizando el potencial de desarrollo existente en el territorio. Esta propuesta define al desarrollo como un proceso de crecimiento y cambio estructural que, mediante la utilización del potencial de desarrollo existente en el territorio, conduce a la mejora del bienestar de la población de una localidad o una región. Cuando la comunidad local es capaz de liderar el proceso de cambio estructural, la forma de desarrollo se denomina «desarrollo local endógeno» (Camagni, 2002; Brunet y Böcker, 2007).

Un instrumento de organización del desarrollo es la planificación estratégica, y que da cabida a la noción de región como cuasi Estado y también como cuasi empresa, usándose el primer concepto como un recordatorio del hecho de ser la cuestión del desarrollo regional una cuestión de naturaleza política, y el segundo concepto como indicación de la necesidad de imbuir a los gobiernos regionales de prácticas empresariales de gestión, en particular, la práctica de la gestión estratégica (Camagni, 2005). Práctica vinculada a la «nueva gestión pública», la cual pretende adoptar los modelos gerenciales o manageriales a la Administración pública (Ballart y Ramió, 2000; Olias de Lima, 2001). Con ello, se aspira a copiar del sector privado sus estrategias orientadas a aumentar la competitividad y el desarrollo de un determinado territorio (Silva, 2005), con lo que se establece, así, nuevas condiciones operativas de ejercicio de la política, acudiendo para ello a la noción de gobernanza urbana, definida como un sistema de gobierno que articula y asocia instituciones políticas, actores sociales y organizaciones privadas en procesos de elaboración y de aplicación de decisiones colectivas capaces de provocar una adhesión activa de la ciudadanía (Ascher, 1995; Kooiman, 1993). Sin embargo, esta visión se ha convertido en algunos casos, y concretamente para Mar del Plata, en una ideología utilizada por los electos y los cuadros administrativos locales, y que no es sino el último avatar de un ejercicio elitista y confiscado del poder urbano (Jessop, 1994; Lovering, 1995; Jouve, 2005). Se trata del acaparamiento de la esfera de la política local por un número de grupos de interés que interactúan con el gobierno local en la definición y aplicación de políticas públicas, lo cual provoca un desdibujamiento entre el sector público y el privado (Schmitter, 1979; Giner y Pérez Iruela, 2003; Solé, 1987)

Basándonos en la literatura sobre desarrollo endógeno, nueva gestión pública y gobernanza urbana, en la investigación pretendíamos objetivar el sujeto real del Plan Estratégico de Mar del Plata (PEM). Concretamente, el objeto que nos ocupa (también podríamos afirmar el sujeto que nos ocupa) está justi- 
ficado en tanto que partimos del supuesto de que la ciudad es un ámbito en que se desarrollan conflictos entre diferentes grupos que compiten por imponer su visión o definición de ciudad. Es decir, se trata de explicitar los esquemas de visión (de apreciación, de percepción y acción) dominantes en el plan, y del que se desprenden acciones que son aceptadas por su relevancia política y determinadas por estrategias de márketing político. A partir de esta consideración, planteamos la siguiente hipótesis de trabajo: las políticas de desarrollo que conlleva el plan (y la propia lógica del plan marplatense) no garantizan un modelo pluralista de desarrollo local, y que tiene que ver con los procesos de estructuración y representación de intereses dentro de la política local.

El método de investigación que hemos elegido es el estudio de caso, en la medida en que, generalmente, se refiere a la investigación de pocos casos, a menudo sólo uno, en un grado de considerable profundidad y a lo largo del tiempo (Coller, 2000). Una metodología que nos permite producir, sociológicamente, representaciones que describan y expliquen una realidad relevante y de características típicas: la planificación estratégica de las ciudades para el desarrollo local. Las técnicas empleadas para la recogida de la información han sido la entrevista semiestructurada y el análisis de contenido como técnica de análisis de las fuentes documentales (López-Aranguren, 1992; Navarro y Díaz, 1999; Vallés, 2000). Para hacer el trabajo empírico, se realizaron distintas actividades, entre las que podemos destacar las siguientes: 1) reconocimiento del entorno institucional del Plan Estratégico de Mar del Plata (PEM); 2) sensibilización; 3) trabajo de campo mediante entrevistas, y 4) procesamiento y análisis de la información. Para el reconocimiento del entorno institucional del PEM, se confeccionó un mapa con las instituciones vinculadas al PEM. En el entramado institucional, aparecen tanto las instituciones que cuentan con alguno de sus miembros en la Comisión Mixta como aquéllas que participan de forma independiente en el proceso de planificación de la ciudad. En forma paralela con las actividades de sensibilización, se confeccionó una guia de entrevista en profundidad semiestructurada, la que fue aplicada durante los meses de febrero y marzo de 2005 a 38 informantes claves, 32 institucionales y 6 integrantes de los equipos asesor externo y técnico local.

\section{Síntesis de resultados}

La observación de que el proceso de la planificación estratégica en Mar del Plata «esta tan politizado y clientilizado» (Independiente12) es una consecuencia de las asimetrías de poder local y que es el origen de fondo de los problemas de la ciudad de Mar del Plata, atravesada toda ella por diferencias sociales. Y es que un plan estratégico es un síntoma de la movilización, por intereses económicos, de la elite del poder local para justificar, técnicamente, una visión política de la ciudad, de modernización gerencial del sistema urbano. Por tanto, un plan estratégico define un modelo de desarrollo local no desde «el conjunto de los intereses de la ciudad», sino desde los intereses político-económicos de la municipalidad y de los sectores empresariales. 
En la documentación oficial, leemos que las actividades «tendentes a la concreción de un Plan Estratégico para Mar del Plata tuvieron su inicio formal en abril de 2001, cuando diversas entidades se autoconvocaron para ese fin» ${ }^{1}$. Así, en junio de 2001, se conformó la Junta Provisoria, cuyo coordinador fue el martillero (subastador) público Donsini, representante del Colegio de Martilleros y Corredores Públicos. En esta fecha, se inició el proceso de deliberación sobre los objetivos y la forma de trabajo de la Junta Provisoria, y en agosto de 2001 se realizó la Asamblea Constitutiva y se conformó la Junta Promotora, en la que participaron más de sesenta instituciones de la ciudad. Como indica un informante «en una reunión que se hizo aquí en el Colegio de Martilleros, reunimos unas 60 instituciones más o menos, en una asamblea que se hizo y se presentó un poco la Comisión Mixta (Junta Promotora) así a la gente, porque no se conocía» (Comision3) ${ }^{2}$. Dicha Junta ${ }^{3}$ comenzó a reunirse quincenalmente, concretamente los martes y en lugares rotativos, a invitación de las entidades miembros, presididas por el coordinador elegido por los miembros de la Junta Promotora, cuya duración estipulada era de tres ${ }^{4}$.

La composición institucional de la Junta Promotora es producto del origen empresarial de la convocatoria realizada por el núcleo institucional inicial, ya que en ambos casos se «buscaron individuos prestigiosos. Cuando vos lo lees encontras tipos que tienen peso económico o apellidos ilustres y hasta empresas de todo tipo. Y bueno, eso fue reconocido posteriormente por el Municipio por una Ordenanza municipal para una Comisión Mixta, donde, a la vez, se meten ellos» (Comision9) ${ }^{5}$. Más concretamente, «a partir de ese momento, esta gente digitó quiénes podían estar en el plan estratégico y quiénes no, y de alguna manera se alentó desde la Municipalidad. Entonces, las personas que hoy conforman la dirección del Plan Estratégico fueron las originales de aquel momento. Con un criterio que aparentaba ser democrático, por un lado desde las gremiales empresarias UCIP (Unión del Comercio, la Industria y la Construcción) y la Bolsa de Comercio, dejaban de lado a APYME (Asamblea de Pequeños y Medianos Empresarios), y, en el momento en el que estaba también CAMECO, también a CAMECO. Y después empresarios notorios y notables, como Cabrales, por ejemplo. Y colegios profesionales y las universidades, la privada y la pública. Eran como 40 instituciones en un primer momento» (Independiente16) ${ }^{6}$.

1. www.planestrategicomdp.org/historia.html

2. Varón, miembro de la Unión del Comercio, la Industria y la Producción (UCIP).

3. Las instituciones y empresas que conformaron la Junta Promotora del PEM son 18 en total: 7 entidades empresariales, 2 entidades gremiales, 4 colegios profesionales, 3 universidades y la representación del Ejecutivo y el Deliberativo de la Municipalidad del Partido de General Pueyrredon.

4. Texto Ordenanza Municipal no 14.957, expediente D.E.: 2002/5/12679, expediente H.C.D.: nota $845-\mathrm{J}-2002$, no registro: $0-9225$, fecha de sanción 10/10/2002, fecha de promulgación 25/10/2002, decreto de promulgación 2800/2002.

5. Varón, miembro de la Universidad Nacional de Mar del Plata.

6. Varón, miembro de la Asamblea de Pequeños y Medianos Empresarios (APYME). 
En los últimos meses del año 2002, la Junta Promotora, constituida en comisión mixta junto a representantes del poder público local, comenzó a deliberar sobre las metodologías de trabajo para la formulación del Plan Estratégico de Mar del Plata. Llegados a este punto, cabe interrogarse respecto a la razón explícita por la que nació el Plan Estratégico de Mar del Plata. La razón está, según la Junta Promotora ${ }^{7}$, en que, a semejanza de otras importantes ciudades del mundo, la ciudad de Mar del Plata necesita un plan estratégico que impulse y guíe su desarrollo. Se trata de una definición ya dogmática de la vara de medir las soluciones y alternativas para los principales problemas coyunturales de una ciudad. Se trata, a su vez, tal y como lo vamos viendo, de un recurso retórico en el que encuentran refugio determinados actores públicos y privados, para propiciar y potenciar «el desarrollo sostenible, integral, participativo, equitativo y solidario de la ciudad $»^{8}$.

La planificación estratégica es un instrumento que se apoya en la capacidad de determinados actores locales de liderar el proceso de desarrollo local, pero ¿qué ocurre cuando «hay resortes que la ciudad no maneja» (Equipo5) ${ }^{9}$, y se habla, continuamente, en la información recogida, de clientelismo, de asimetrías de información, de ocultamiento de datos, y que se pide como colofon del Plan Estratégico armar una agencia de desarrollo local?, pues «lo pidió el intendente y lo pidió la Comisión Mixta, elaborar una propuesta» (Equipo2) ${ }^{10}$. Y la propuesta estaba en articular la Agencia de Desarrollo Local con la Comisión Mixta, asumiendo que quien «tiene mucho peso para decidir es el Municipio, digamos, y me parece que es lo más lógico en este momento. El Municipio, y cuando me refiero al Municipio me refiero al Ejecutivo y al Legislativo, porque es quien ha financiado la mayor parte de este proceso, porque, digamos, hay algunas cuestiones que no se pueden desconocer» (Equipo2). Como son los condicionamientos políticos, y ello en un contexto en que el se «sigue teniendo mucho miedo al tema de la participación, desde todos los sectores, no solamente desde los políticos tradicionales, también en los empresarios» (Equipo4) ${ }^{11}$.

En la dinamización de la metodología estratégica, se da una situación compleja en la que «la gente tenía problemas en distinguir entre lo real y lo deseable, o entre lo deseable y lo posible. Entonces, sobre todo en el aspecto de la ciudad que aspiraba, "yo quiero esto pero es imposible, jamás va a pasar esto"” (Equipo4). De ahí que, para ahondar más «en las variables internas y exter-

7. De acuerdo con la Junta Promotora, ésta «se conformó para impulsar el Plan Estratégico de la Ciudad. Sus integrandes representan a distintas instituciones locales, participando en forma voluntaria y ad honorem, con la convicción de avanzar a paso firme, con una tarea que nos beneficiará a todos los marplatenses» (Documento de Junta Promotora del Plan Estratégico de Mar del Plata «Avanza el Plan Estratégico para la ciudad», fecha sin especificar).

8. Informe de la Comisión Técnica de la Junta Promotora del Plan Estratégico de Mar del Plata "2a Asamblea Plan Estratégico», diciembre de 2002.

9. Mujer, miembro del Área Socioinstitucional.

10. Mujer, encargada de la coordinación del equipo técnico local.

11. Varón, miembro del Área Urbano-ambiental. 
nas, o sea, fortalezas, debilidades, oportunidades y amenazas» (Equipo2), se armaron escenarios "posibles para el desarrollo futuro de la ciudad» (Equipo2). A partir de que Mar del Plata está en una situación y «¿cómo hacer para estar en otra situación, desde qué línea de actuación se puede lograr? Y así se pudo definir, se concluye por una parte importante de nuestros informantes, las líneas estratégicas» (Equipo2) del desarrollo de Mar del Plata. Esto requería «asumir un nuevo rol desde el Estado local, una línea específica de acción que apareció ya en el diagnóstico», la línea de transformación municipal ya estaba en el diagnóstico. Así, «desde el diagnóstico, que está sumamente convalidado, legitimado y reclamado por todos, explícitamente aparecían los problemas [...] Sí también apareció en el diagnóstico mucha capacidad y liderazgo del intendente, digamos, se rescata al intendente, a la figura del intendente, su habilidad para negociar, para conducir» (Equipo 2$)^{12}$. Desde este punto de vista, el diagnóstico constituye un respaldo al intendente. Por tanto, lo que se manifiesta en el despliegue de la metodología estratégica es la formación de un saber —o discurso de la planificación-, que va a permitir y asegurar el ejercicio del poder del intendente ${ }^{13}$, y además desde determinados sectores oficiales se efectúa «una crítica feroz al Estado tradicional y a su incapacidad de gestión» (Equipo2).

O sea, como lo que el «intendente dijo en sus discursos "hay que dar un salto cualitativo, no se puede seguir actuando de bombero, para la crisis está bien, ahora hay que planificar". Esa necesidad está, en el discurso del intendente» (Equipo2) ${ }^{14}$. Por otro lado, «los propios funcionarios que participan del Gabinete municipal [...] pidiendo que se los ayude en esta tarea de planificar» (Equipo2). El tema es «acercar el Municipio a la gente y viceversa. Yo creo que este lenguaje (de la nueva gestión pública)», introdujo «una nueva concepción de lo que es el rol del Estado» (Equipo2). Se habla, pues, de nuevos modelos de gestión, de nueva gestión pública, de nueva política de Estado local, y lo que hizo el gobierno de Katz fue «negociar con algunos sectores políticos», para "empezar por aquello que es posible, es viable, es factible y lo están viendo" (Equipo2). Pero, "esto es un gobierno de mucha decisión política, a diferencia del gobierno anterior de Aprile, que era el típico radical (UCR),

12. Se nos informa que el «intendente participó en todos los talleres. Vos tenías sentado en los talleres del Plan Estratégico al intendente y a todo el gabinete. Tenías el Concejo Deliberante. La voluntad política (como elemento de factibilidad de los proyectos) no se lo interrogaba mucho, porque en realidad los tenía ahí [...] Y el otro condicionante para percibir voluntad política fue que el último taller, el del primero de diciembre, lo abrió el intendente. Es decir, el cierre de la etapa de formulación la abrió él y dijo una serie de cosas» (Equipo5).

13. «El respaldo del Municipio al Plan proviene de la decisión del intendente, y después por Comisión Mixta se complementa. O sea, nosotros nos integramos como Equipo técnico, nuestra primera reunión fue en el despacho del intendente, y nos presentó a todos los secretarios y todo lo demás» (Equipo5).

14. Un discurso para el que el Plan Estratégico ha de quedar "como una especie de plato volador que solo pensaba en el futuro mientras que la vida cotidiana corría por otros canales» (Equipo1). 
como dicen "caballo de plaza" que no te caga pero no te lleva a ningún lado. Pero éste [Katz] tiene una gran voluntad política, entonces vio que a través de este tipo de cosas podía mantener una imagen de progresismo, una imagen de participación y de compromiso con lo que allí se resolvía. Pero siguió alimentando los viejos vicios, porque cada una de estas organizaciones que son los que "cortan el bacalao" en Mar del Plata, puso un hombre en cada una de las distintas instancias. En el segundo concurso pusieron uno de FASTA, uno de la Municipalidad, uno de la UCIP... Es decir, los candidatos que ellos querían que estuviesen ahí. Y esto no se dio solamente en esto, porque cuando sube Katz le pide a la Cámara Argentina de la Construcción que le pongan un hombre para el tema de la obra pública» (Independiente16).

En el perfil corporativo que se vislumbraba en la conformación de la Comisión Mixta, se refleja la búsqueda por parte de las dirigencias corporativas locales de un posicionamiento mejor y una defensa más eficaz de sus intereses particulares ${ }^{15}$, y es que "yo creo que la parte de Comisión Mixta es exclusivamente política, que es un nivel donde se toman las decisiones, porque es el órgano de gobierno de este Plan. Y lo que tuvo es que esta falta de apertura respecto al resto de las instituciones es como tener un interés muy concentrado, que incluso comparten muchas de las instituciones que componen la Comisión Mixta, como que van en busca del mismo interés. Y es como que te da a pensar que es un Plan para pocos» (Independiente14). Y que se lleven a cabo en tanto que una ventaja del tipo de planificación realizada, es que «aparentemente desaparecen los conflictos de clase. Digamos, en ningún momento se desató en ninguna mesa, que yo recuerde, un tema de conflicto de clase, que para mí personalmente sigue siendo un tema de fondo» (Equipo4).

Puede leerse, en una comunicación de los Autoconvocados ${ }^{16}$, lo siguiente: «imagine que el Gobierno Municipal de su ciudad decide destinar una suma importante de dinero para que usted y otros ciudadanos propongan un plan de desarrollo para su Partido. Suponga que ese dinero es manejado por un grupo reducido, que por su composición no es representativo de la heterogénea composición de la ciudadaní. Suponga que ese mismo gobierno desconoce la existencia de ese plan y actúa por fuera de (y contradiciendo) esa propuesta. Deje de imaginar: la actualidad del Plan Estratégico de Mar del Plata y el Partido de General Pueyrredon no difiere de esta supuesta situación hipotética [cursiva de los Autoconvocados

15. Se nos indica que «en realidad lo único que encontramos fueron Agencias de Desarrollo Económico, más vinculado al tema de pymes y al tema de empleo. Sentíamos que habíamos doblado la apuesta de Monteverde y del proceso de planificación. Sentíamos que retrocedíamos si armábamos... el diagnóstico de esta ciudad es básico y es fragmentado, y que las instituciones no saben trabajar de manera asociada y que los intereses son sectoriales» (Equipo5).

16. Autoconvocados PEM es un grupo de instituciones marplatenses que se autoconvocaron, por un lado, para debatir más en profundidad los temas que se discutían en los talleres de diagnóstico y formulación y, por otro, para conseguir ampliar la participación institucional en la Comisión Mixta y en la Asamblea Representativa de Instituciones. Este grupo llegó a reunir, durante el 2004, a más de sesenta representantes institucionales. 
PEM]. Antes de que lea lo que sigue, queremos dejar en claro que NOS ANIMA E ILUSIONA LA EXISTENCIA DEL PLAN ESTRATÉGICO: desde hace más de un año actuamos para difundir esta herramienta de planificación». Y concluyen diciendo que «creemos que los pueblos deben tener un papel activo en el diseño de acciones en pos de construir los caminos hacia su desarrollo social y económico. Precisamente, el Plan Estratégico de Mar del Plata y el Partido de General Pueyrredon (PEM) se propone como un plan PARTICIPATIVO: elaborado con la ciudadanía y no por un grupo de iluminados para los demás» (las cursivas son de la nota) ${ }^{17}$.

Esta postura crítica asumida por los Autoconvocados PEM les lleva a declarar que "nos inquieta la inexistencia de un organismo de control al que la Comisión Mixta deba rendir cuentas de lo actuado. Nos alarma descubrir que el Reglamento Interno de la Comisión Mixta impide que se incorporen a la misma nuevas instituciones antes de agosto de 2005, cuando el Plan estará ya formulado y posiblemente implementado. Esta situación se agrava al conocer que las eventuales renovaciones dependen de la voluntad de los representantes de las instituciones que conforman la Comisión. Si el Plan Estratégico es de y para todo el Partido de General Pueyrredon, ¿por qué las decisiones quedan en manos de un grupo reducido de instituciones, que carecen de representatividad de amplios sectores de la comunidad? Si no podemos asegurar que nuestras opiniones sean tenidas en cuenta, ¿estamos participando realmente, o sólo convalidando lo ambicionado por unos pocos?» ${ }^{18}$. Si se trata de dar nombre a la queja de los Autoconvocados, este nombre es «corporativismo local».

\section{Conclusión}

Con distinta suerte, a nivel de apropiación y de éxito, se vienen desarrollando planes estratégicos en Argentina en un marco que va de convencimientos profundos en cuanto a su utilización, como «nuevo modo» de construcción de ciudad, a otros que se asocian a una especie de aggiornamento del Gobierno local, que se adecua a una «nueva moda» de gestión del conjunto de actividades de un sistema productivo local. En esta nueva instancia, el enfoque estratégico y participativo de la planificación creció en "popularidad» entre los agentes del Gobierno local. Sin embargo, en la realidad de Argentina, el cambio de paradigma, desde una planificación urbana tradicional hasta una planificación estratégica y participativa, no sólo no se ha dado definitivamente, sino que también hemos observado cómo la existencia de jerarquías estructurales, a nivel regional y local, no garantiza un modelo pluralista de desarrollo local. Dichas jerarquías llevan a que no se tome en consideración a todos los actores del desarrollo, sin excepción ni exclusividad, sino, más bien, cómo determinados grupos de interés (UCIP, Cámara de Comercio, Centro de 
Constructores y Anexos...) se apropian de la formulación e implantación del Plan Estratégico a efectos de lograr una gestión privada de intereses públicos ajustada a sus intereses.

\section{Bibliografía}

AmIN, S. (1974). El desarrollo desigual. Barcelona: Fontanella.

- (1985). La acumulación a escala mundial: crítica de la teoría del subdesarrollo. México, DF: Siglo XXI.

ANDERSEN, A. (1989). Experiencias en planificación estratégica de ciudades. Madrid: PROMADRID.

ARroYo, D. (1997). «Estilos de gestión y políticas sociales municipales en la Argentina». En: Delgado, D. (comp.). Hacia un modelo de gestión local. Municipio y sociedad civil en la Argentina. Buenos Aires: Oficina de Publicaciones del CBC-UBA, p. 32-51.

AsCHeR, F. (1995). Metápolis ou l'avenir des villes. París: Odile Jacob.

BAGNASCO, A.; LE GALĖS, P. (1997). «Les villes europeennes comme société et comme acteur». En: BAGNASCO, A.; LE GALÈs, P. (eds.). Villes en Europe. París: La Découverte.

Ballart, X.; Ramió, C. (2000). Ciencia de la Administración. Valencia: Tirant lo Blanch.

BASUALDO, E. (2001). Modelo de acumulación y sistema político en la Argentina. Notas sobre el transformismo argentino durante la valorización financiera (1976-2001). Bernal: Universidad Nacional de Quilmes.

BECATTINI, G.; RULLANI, E. (1979). «Local systems and global connections: The role of knowledge». En: CossentinO, F.; PYKe, F.; SEnGEnBerger, W. (eds.). Local and regional response to global pressure: The case of Italy and its industrial districs, International Institute of Labour Studies. Génova, p. 61-107.

BECK, U. (1998). La sociedad del riesgo. Hacia una nueva modernidad. Barcelona: Paidós.

BRUNET ICART, I.; BÖCKER ZAVARO, R. (2007). Desarrollo, industria y empresa. Madrid: Tecnos.

CAMAGNI, R. (2002). «Papel económico y contradicciones espaciales de las ciudades globales: el contexto funcional, cognitivo y evolutivo». En: BECATTINI, G.; COSTA, M.; TrulléN, J. (coords.). Desarrollo local: teorías y estrategias. Madrid: Civitas Ediciones.

- (2005). Economía urbana. Barcelona: Antoni Bosch.

CATENAZZI, A.; ReESE, E. (2001). La construcción de estrategias de desarrollo local en las ciudades argentinas: Análisis sobre los nuevos escenarios y sus implicancias en la planificación participativa. Alcances y limitaciones en experiencias argentinas. Curso de Posgrado Desarrollo local en áreas metropolitanas, módulo 3, profesor Eduardo Reese. En: <http://www.urbared.ungs.edu.ar/textos/Mod3EReese.doc>.

Cea D’ancona, M. A. (1996). Metodología cuantitativa: Estrategias y técnicas de investigación social. Madrid: Síntesis.

COLLER, X. (2000). Estudio de casos. Madrid. Centro de Investigaciones Sociológicas.

DufFIELD, M. (2004). Las nuevas guerras en el mundo global. La convergencia entre desarrollo y seguridad. Madrid: Los Libros de la Catarata.

FERNÁNDEZ GÜELL, J. (1997). Planificación estratégica de ciudades. Barcelona: Gustavo Gili. 
García Ferrando, M.; BÁNEZ, J.; Alvira, F. (1998). El análisis de la realidad social. Métodos y técnicas de investigación. Madrid: Alianza Editorial.

Giner , S.; PÉrez Yruela, M. (2003). «De la sociedad masa a la sociedad corporativa». En: GINER, S. (coord.). Teoría sociológica moderna. Barcelona: Ariel.

Grupo DE LisboA (1995). Limits to Competition. Nueva York: MIT Press.

Harvey, D. (1989a). The conditions of postmodernity. Oxford: Basil Blackwell.

- (1989b). "From Managerialism to Entrepreneurialism: the Transformation in Urban Governance in Late Capitalism». Geographiska Annaler, 71 B, p. 3-17.

JESSOP, B. (1994). "The transition to post-fordism and the Schumpeterian Workfare State». En: LoAder, B.; Burrows, R. (eds.). Towards a Post-Fordist Welfare State? Routledge, p. 13-38.

Jouve, B. (2005). Cuestiones sobre gobernanza urbana. Barcelona: Fundació Carles Pi i Sunyer.

KÖHLER, H.-D. (1999). "Corporativismo local, ¿una estrategia de consenso para el desarrollo?». En: RodríguEZ GUTIÉRREZ, F. (ed.). Manual de desarrollo local. Gijón: Ediciones Trea, p. 91-110.

KoOIman, J. (1993). Modern Governance. Londres: Sage.

LAL, D. (1983). The Poverty of Development Economics. West Sussex: Institute of Development Economic Affairs.

LASH, S.; URRY, J. (1987). The end of organizad capitalism. Madison: University of Wisconsin Press.

LÓpez-Aranguren, E. (1998). "El análisis de contenido». En: García FERrando, M.; IBÁÑ̃Z, J.; AlVIRA, F. (comp.). El análisis de la realidad social. Métodos y técnicas de investigación. Madrid: Alianza Editorial.

LOVERING, J. (1995). "Creating Discourses Rather Than Jobs: the Crisis in the Cities and the Transition Fantasies of Intellectual and Policymakers». En: HeALEY, P.; Cameron, S.; Davoudi, S.; Graham, S.; Madani-Pour, A. (eds.). Managing Cities. The new urban context. Chichester: John Wiley \& Sons.

Mantobani, J. (2003). La planificación estratégica en las ciudades intermedias de Argentina. IV Seminario Internacional de Estudios Urbanos, 20 a 23 de agosto de 2003. Tandil.

Marshall, A. (1963). Principios de economía Madrid: Aguilar.

Navarro, P.; Díaz, C. (1999). "Análisis de contenido». En: Delgado, J. M.; GUTIÉRREZ, J. (coord.). Métodos y técnicas cualitativas de investigación en ciencias sociales. Madrid: Síntesis.

OlíAs De Lima, B. (2001). Madrid. La nueva gestión pública.

PIORE, M.; SABEL, Ch. (1990). La segunda ruptura industrial. Madrid: Alianza Editorial. POLlaRD, S. (1987). La génesis de la dirección de la empresa moderna. Madrid: MTSS. PORTER, M. (1990). La ventaja competitiva de las naciones. Esplugues de Llobregat: Plaza \& Janés Editores.

SASSEN, S. (1996). Losing control? Sovereignty in an age of globalization. Nueva York: Columbia University Press.

SCHMITTER, P. (1979). «Still the century of corporatism?». Review of Politics, núm 36, p. $85-131$.

SEGURA, J. (2005). "La economía mundial entre 1973 y el siglo XXI: el final del crecimiento dorado». En: Comín, F.; Hernández, M.; Llopis, E. (eds.). Historia económica mundial. Siglos X-XX. Barcelona: Crítica.

Silva LiRA, I. (2005). «Desarrollo económico local y competitividad territorial en América Latina». Revista de CEPAL, núm. 85, abril. En: <http://www.eclac.cl>. 
Solé, C. (comp.) (1987). Corporalismo y diferenciación regional. Madrid: Ministerio de Trabajo y Seguridad Social.

STORPER, M. (1990). «Industrialization and the regional question in the Third World: lessons of post-imperialism; prospects of post-Fordism». International Journal of Urban and Regional Research, núm. 14, 3. Nueva York.

VAlLes, M. S. (2000). Técnicas cualitativas de investigación social. Reflexión metodológica y práctica profesional. Madrid: Síntesis.

VÁZQUEZ BARQUERO, A. (1999). Desarrollo, redes e innovación: Lecciones sobre el desarrollo endógeno. Madrid. Pirámide.

- (2005). Las nuevas fuerzas del desarrollo. Barcelona: Antoni Bosch.

Williamson, J. (1990). Latin American Adjustment. Washington DC: Institute of International Economics. 